\title{
Partial Fire Protection of Composite Slabs
}

\author{
C. Both \\ Section Steel Structures, Faculty of Civil Engineering, Delft University of Technology, \\ Stevinweg, 1, NL 2628, CN, Delft, The Netherlands

\section{J. W. B. Stark \& L. Twilt} \\ TNO, Building and Construction Research, Lange Kleigweg, 5, Rijswijk, Postbus 49, \\ NL2600 AA, Delft, The Netherlands
}

\begin{abstract}
An international research project on fire-exposed composite structures has been conducted jointly between research institutes in the Netherlands, France and Luxembourg. The Centre Technique Industriel de la Construction Metallique (CTICM, France) and Arbed, Luxembourg, focus on composite steel-concrete beams. TNO Building and Construction Research and Delft University of Technology are concerned with composite slabs. The aim of this project is to develop simple calculation rules for fire resistance assessment. Funding is provided by the European Coal and Steel Community.

The fire resistance of continuous composite slabs can economically be improved by means of partial protection near internal supports. In this paper, the results of an initial investigation are reported.
\end{abstract}

\section{NOTATION}

$L \quad$ Length of span (m)

$L_{\text {prot }}$ Length of protected area of composite slab (m)

$M$ Bending moment ( $\mathrm{N} \mathrm{m})$

$M_{\mathrm{p}}^{-}$Hogging plastic moment capacity $(\mathrm{N} \mathrm{m})$

$M_{\mathrm{p}}^{+}$Sagging plastic moment capacity $(\mathrm{Nm})$

$q$ Distributed load $\left(\mathrm{N} / \mathrm{m}^{2}\right)$

J. Construct. Steel Research 0143-974X/93/\$06.00 (C) 1993 Elsevier Science Publishers Ltd, England. Printed in Malta 
$t \quad$ Time (min)

$z \quad$ Distance $(\mathrm{m})$

$\delta \quad$ Reduction of system length/translation plastic hinge (m)

$\phi \quad$ Diameter of reinforcement bar (mm)

\section{INTRODUCTION}

Composite steel/concrete construction is becoming quite popular in Europe. Considerable research effort during the last decade has focused on composite columns, beams and slabs, see, e.g. CIDECT and ECSC sponsored research projects. ${ }^{13}$

From experimental evidence, it was concluded that existing rules for the calculation of the behaviour of fire-exposed composite slabs often leads to conservative solutions. Furthermore, the range of common applications had grown beyond the existing calculation rules. It was felt that existing rules lacked a fundamental basis, in order to optimally design and evaluate fire-exposed composite slabs.

Therefore, a research project was started in 1989, in which TNO and both Delft and Eindhoven Universities of Technology jointly share numerical and experimental research activities with respect to the behaviour of fire-exposed composite slabs. The project aims at gaining more insight into the behaviour of fire-exposed composite slabs by means of the development of numerical models and their validation based upon a limited number of full-scale fire tests. The final goal of this research project is the establishment of simple calculation rules and rules of thumb, which allow easy and fast assessment of the fire-behaviour of composite slabs.

The research comprises two phases. In the first phase, main attention was on the behaviour of simply supported slabs, though one test was done on a two-span slab. Pilot versions of special purpose two-dimensional numerical models were developed, ${ }^{4}$ allowing:

- the analysis of two-dimensional transient heat flow;

- the calculation of moment curvature $(M-\kappa)$ diagrams;

- the calculation of deflections.

From both experimental and numerical investigations in phase 1, the following conclusions were drawn:

- the models reasonably predict the results of fire tests on simply supported slabs;

- the models need improvement for continuous slabs. 
It appeared from tests that thermal shielding near an internal support had significant influence on the thermal behaviour and, as a consequence, on the mechanical behaviour. Furthermore, the models could not predict the failure mechanism of the tested continuous slab (which had a relatively high ratio of hogging reinforcement of $0.52 \%$ ).

In the present second phase of the research, which focuses on continuous slabs, use is therefore being made of the general purpose threedimensional finite element package DIANA. ${ }^{4}$ (DIANA is an acronym for Displacement ANAlysis. The finite element program is a trademark of the DIANA Analysis B. V., the Netherlands.)

A start was made on the numerical investigation of the influence of internal supports on both the thermal and mechanical responses of continuous slabs. This paper concentrates on the positive effect of thermal shielding and partial protection of composite slabs near internal supports.

\section{BEHAVIOUR OF FIRE-EXPOSED CONTINUOUS SLABS}

Consider a continuous slab with two spans of $L=4 \mathrm{~m}$ and a total load of $q=6 \mathrm{kN} / \mathrm{m}^{2}$, Prince PSV 73 steel decking (thickness $0.75 \mathrm{~mm}$ ) and $70 \mathrm{~mm}$ normal weight concrete. Hogging reinforcement $\phi 8-200$ and sagging reinforcement $\phi 8-220$ are provided (FeB500 yield strength $500 \mathrm{~N} / \mathrm{mm}^{2}$ ). The compression strength of concrete is $30 \mathrm{~N}-\mathrm{mm}^{2}$ (see Fig. 1).

During fire-exposure (from below), thermal gradients will develop in the cross-section of the composite slab, imposing large thermal curvatures. As a result, the reaction force at the internal support will grow, soon leading to the occurrence of a plastic hinge (typically after 10-20 min). Increasing temperatures at the internal support cause a reduction of the mechanical properties such as yield stress and Young's modulus (see Fig. 2). Therefore, the hogging plastic moment capacity will decrease and a redistribution of
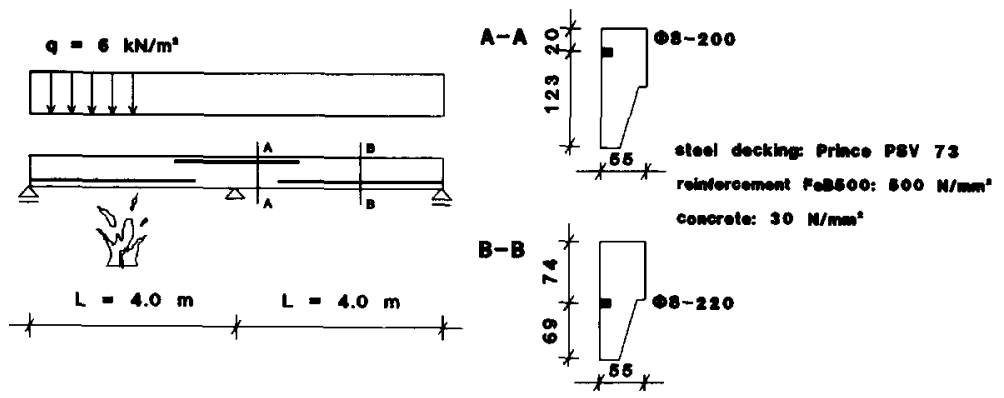

Fig. 1. Geometry and static system of the investigated case. 


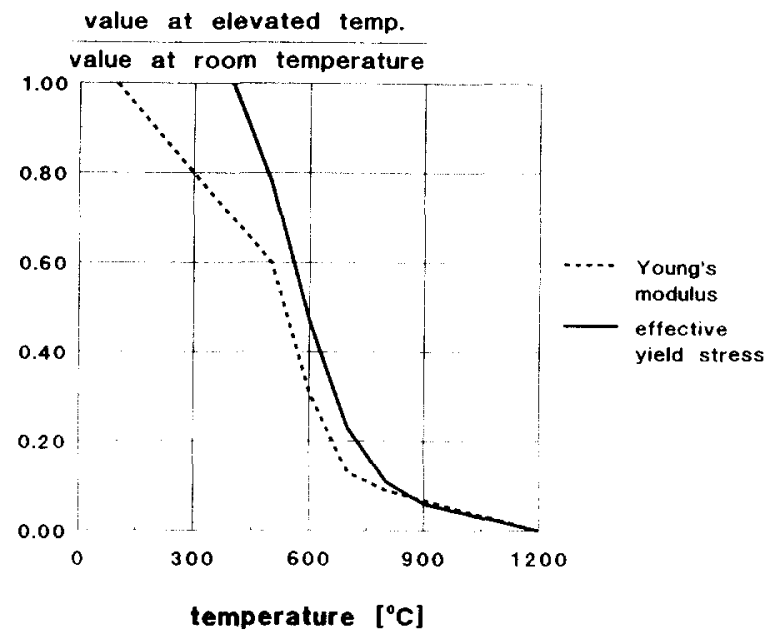

Fig. 2. Reduction of mechanical properties of hot-rolled steel at elevated temperatures. ${ }^{5}$ _..-, Young's modulus; -..._....., effective yield stress.

bending moments takes place. The redistribution will continue, until another plastic hinge occurs near midspan. This creates a plastic failure mechanism, (see Fig. 3).

The period during which the two-span slab exposed to ISO-standard fire can fulfil its load-bearing function is called the fire resistance. This is equal to the time required to form a plastic mechanism. Requirements with

Fig. 3. Redistribution of bending moments and development of failure mechanism in a fire-exposed two-span slab. 


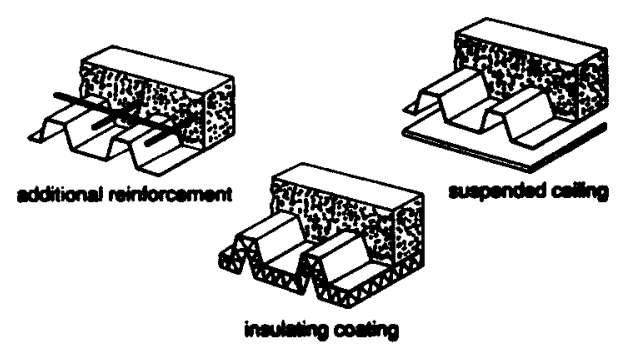

Fig. 4. Options to improve the fire resistance of composite slabs.

respect to the fire resistance regarding structural failure are normally referred to in classes 60,90 and $120 \mathrm{~min}$. The fire resistance of continuous slabs can be improved by providing additional hogging reinforcement near internal supports. Alternatively, a suspended ceiling or insulating coatings can be used (see Fig. 4).

By means of these alternatives, the temperature development is positively influenced (i.e. temperatures are lower), and as a consequence the decrease in mechanical properties is delayed, which in turn yields higher plastic moment capacity. Completely insulating the composite slab, or the use of a suspended ceiling, is expensive when compared to the application of additional hogging reinforcement.

Internal supports are normally made of hot rolled steel sections. If a fire resistance of, say, $60 \mathrm{~min}$ or more is required, then these sections have to be protected. When sprayed mortar was used for this purpose, the question arose as to whether the fire resistance of the composite slab could be improved by putting a small additional amount of protective material on the composite slab as well (see Fig. 5). In that way, partial protection may prove to be an economical alternative.

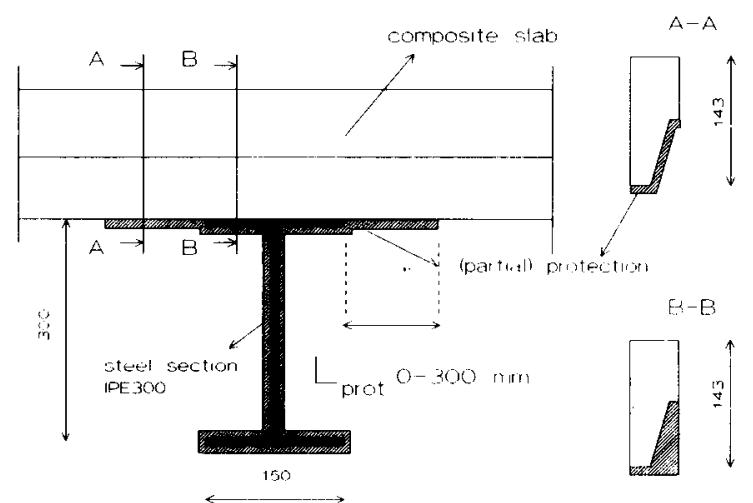

Fig. 5. Principle of partial fire protection of composite slabs near internal supports. 


\section{TRANSIENT HEAT FLOW NEAR INTERNAL SUPPORTS}

In a first attempt, an insulated IPE300 steel beam was numerically investigated. The thickness of the insulating materal (sprayed mortar) was $10 \mathrm{~mm}$. The thermal properties of the insulating material were based on the results of tests by TNO and derived from Ref. 6. The thermal properties of steel and concrete were adopted from EC4. ${ }^{5}$

Three calculations were made, in which the three-dimensional transient heat flow near internal supports was studied (see Fig. 5 and Table 1).

A typical finite element mesh is shown in Fig. 6. Due to symmetry, only half of the steel section needs to be modelled, whereas also only half of one

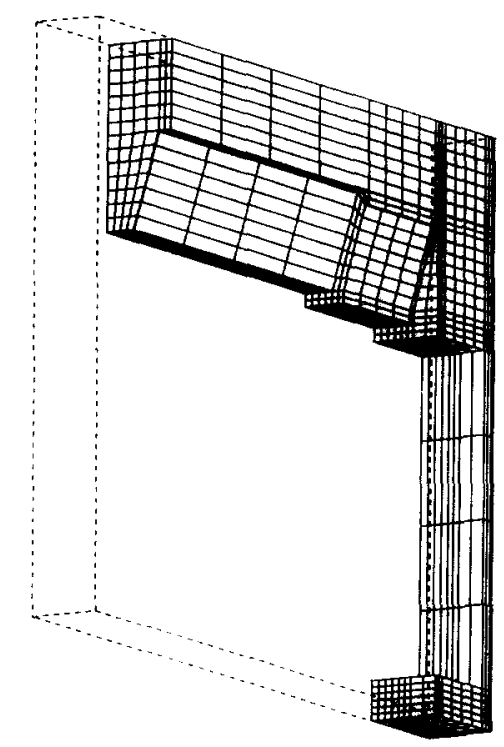

Fig. 6. Finite element mesh: only half of one rib of the slab and half of the IPE steel section are modelled because of symmetry.

TABLE 1

Calculations of Three-Dimensional Transient Heat Flow near Internal Insulated Support (calculations with a total of 3305 elements, took some $3000 \mathrm{CPU}$-s on a HP9000 work station)

\begin{tabular}{cc}
\hline & Partial protection slab \\
\hline 1 & $L_{\text {prot }}=0 \mathrm{~mm}$ \\
2 & $L_{\text {prot }}=100 \mathrm{~mm}$ \\
3 & $L_{\text {prot }}=300 \mathrm{~mm}$ \\
\hline
\end{tabular}



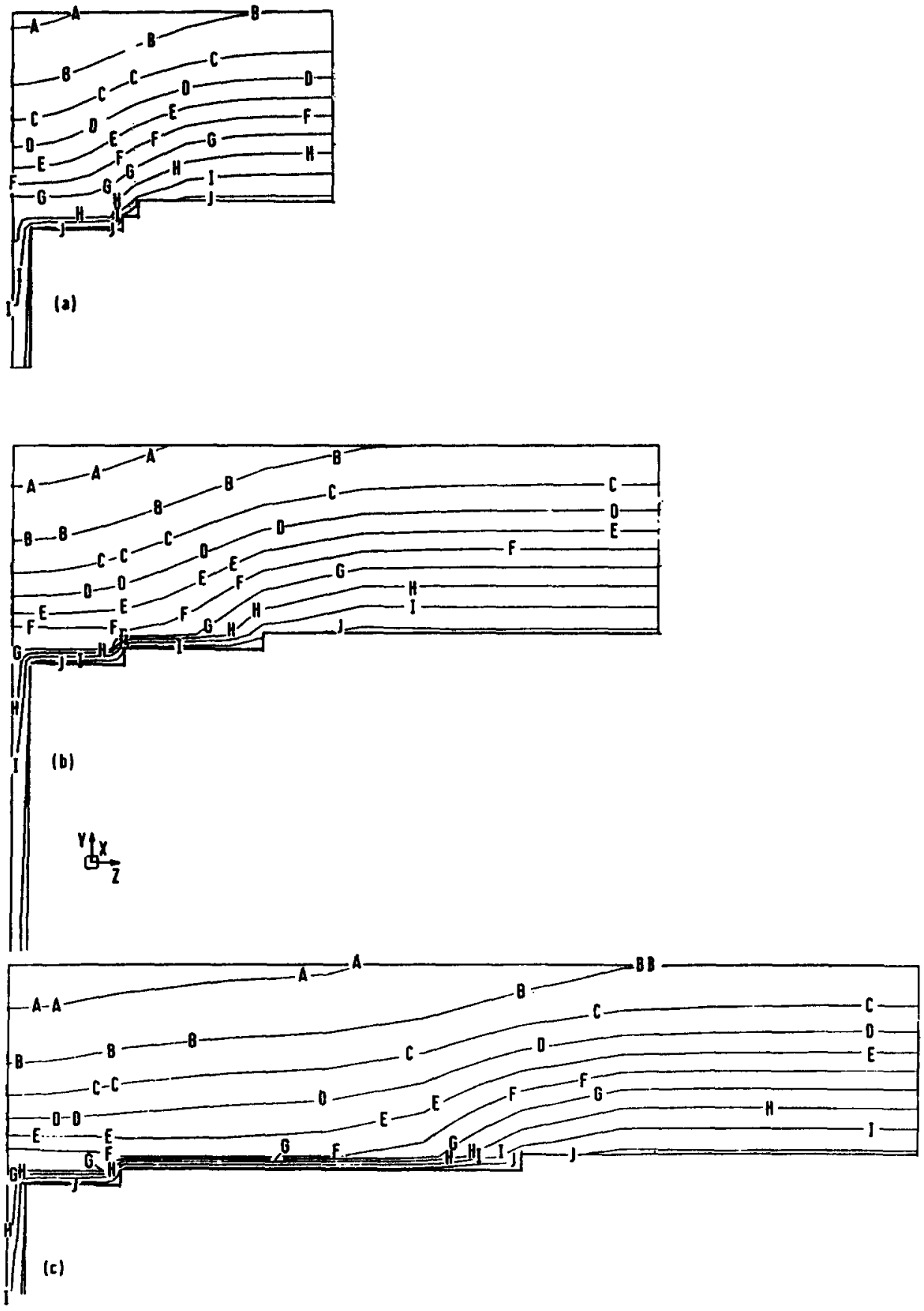

Fig. 7. Calculated temperature distributions after $120 \mathrm{~min}$ fire-exposure for all calculations (in ${ }^{\circ} \mathrm{C}$ ): (a) $L_{\text {prot }}=0 \mathrm{~mm}$; (b) $L_{\text {prot }}=100 \mathrm{~mm}$; (c) $L_{\text {prot }}=300 \mathrm{~mm}$. Isotherms $\left({ }^{\circ} \mathrm{C}\right.$ ): J, 1E4; I, 900; H, 800; G, 700; F, 600; E, 500; D, 400; C, 300; B, 200; A, 100. 
rib of the composite slab is modelled. Use is made of the general purpose three-dimensional finite element package DIANA. In a former publication, the validation of this package for three-dimensional transient heat flow near internal supports, on the basis of test results was described (see Ref. 7). It is noted here, that in the case of $L_{\text {prot }}=0$ (calculation 1), the voids between the ribs of the slab on the steel section are filled with insulating material. Calculation 1 is referred to in the paper as the 'unprotected slab'.

Typical temperature profiles for all calculations after $120 \mathrm{~min}$ of standard fire exposure are plotted in Fig. 7. In Fig. 7, isotherms are plotted in the plane of symmetry of the composite slab, for temperatures in the range 100 $1000^{\circ} \mathrm{C}$. From Fig. 7 , it appears that the area in which the temperatures are influenced by the insulated support is approximately equal to the length of the protected area plus half of the height of the composite slab. Furthermore, it can be seen that directly above the steel section, temperatures are significantly, even up to $200^{\circ} \mathrm{C}$, lower than in the uninfluenced area. As a consequence, the hogging plastic moment capacity of the composite slab is positively influenced, as will be discussed in more detail in the next section.

\section{MECHANICAL RESPONSE}

\section{Hogging plastic moment capacity}

The starting point for the calculation of the mechanical response is the temperature distribution calculated with the three-dimensional model. Use is made of the computer program for the calculation of $M-\kappa$ diagrams. ${ }^{4}$ In the calculations, the following assumptions are made:

— uni-axial stress state;

- Bernoulli hypothesis holds for cross-sections of composite slabs;

- conditions which allow use of elementary plastic theory (especially adequate deformation capacity of the hot rolled reinforcement is assumed);

- mechanical properties at elevated temperatures are derived from EC4. ${ }^{5}$

Furthermore, the contribution of the steel sheet to the load-bearing capacity is neglected, as well as the influence of the tension stiffening of concrete (i.e. the tensile strength of the concrete is neglected).

The results of the calculations in terms of plastic moment capacity as a function of the distance from the centre of the internal support are given in Fig. 8, for specific time steps during fire exposure. From Fig. 8 it is evident 

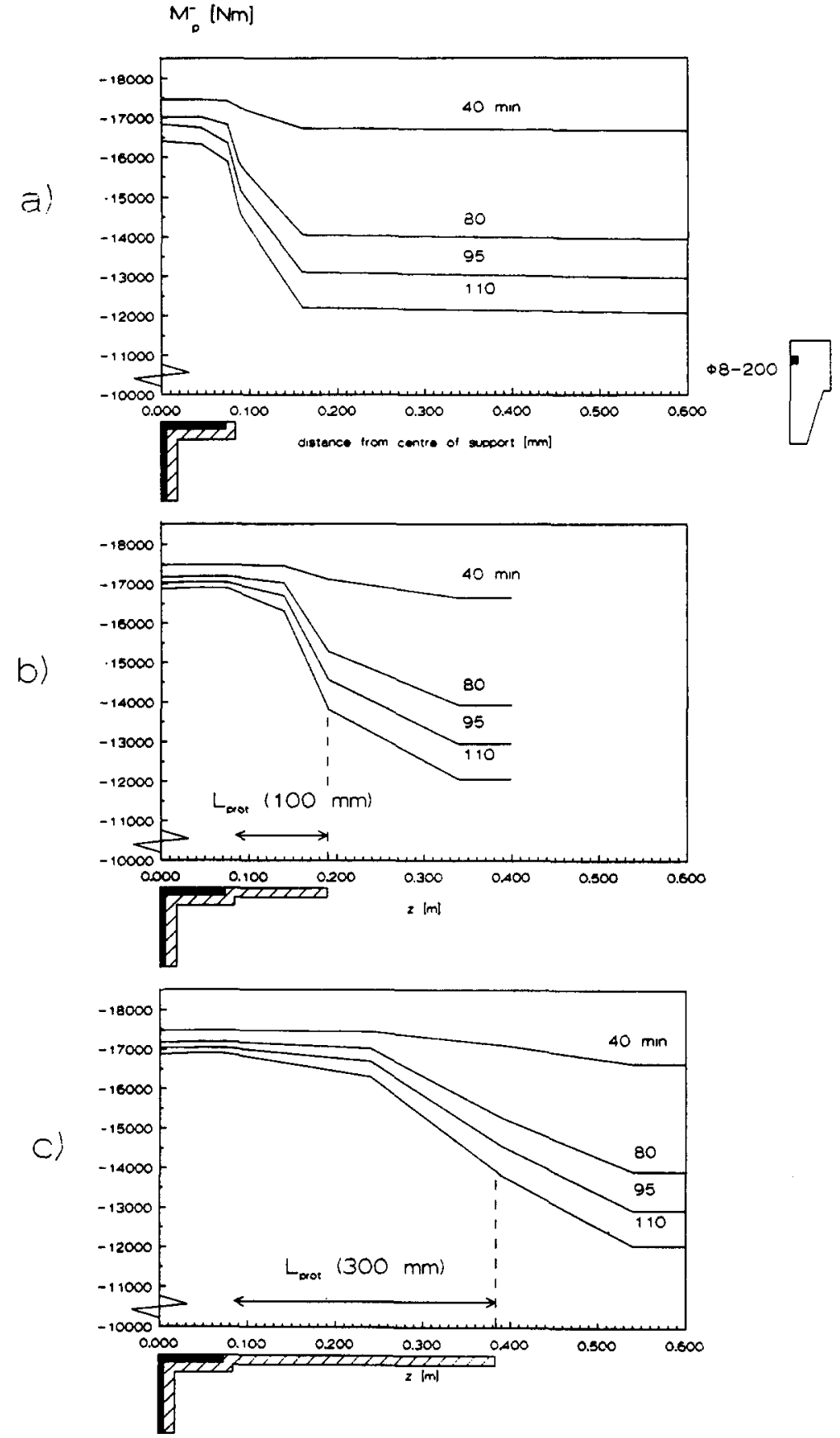

Fig. 8. Calculated hogging plastic moment capacity $\left(M_{\mathrm{p}}^{-}\right)$of a composite slab as a function of the distance from the centre of the insulated interal support (z) during fire exposure: (a) $L_{\text {prot }}=0 \mathrm{~mm}$; (b) $L_{\text {prot }}=100 \mathrm{~mm}$; (c) $L_{\text {prot }}=300 \mathrm{~mm}$. 
that, in accordance with Fig. 7, the area in which the hogging moment capacity is positively influenced is approximately equal to the length of the protected area plus half of the height of the composite slab. Furthermore, it appears that, especially for the unprotected slab, the transition area in which the hogging moment capacity decreases to its 'unaffected' level is very small.

Another important conclusion is that the hogging plastic moment capacity at the centre of the support for protected slabs is hardly influenced during $110 \mathrm{~min}$ of fire exposure. In fact it appeared that after $180 \mathrm{~min}$, the hogging moment capacity had decreased by as little as $11 \%$.

\section{Fire resistance}

As described above, a plastic hinge will develop at the internal support in an early stage of fire exposure. From that time on, the distribution of bending moments can easily be determined from equilibrium.

Consider the unprotected composite slab after, say, $80 \mathrm{~min}$ of fire exposure. Comparing the distribution of bending moments near the internal support with the calculated hogging plastic moment capacity, it appears that the hogging plastic moment capacity is not sufficient: bending moments are larger (see Fig. 9). This means that the plastic hinge can no longer stay directly above the centre of the support, but will move away from the support. From Fig. 9 it follows that the plastic hinge will move over a distance $\delta$ of approximately $0.15 \mathrm{~m}$. Thus the failure mechanism transforms into a mechanism with four plastic hinges

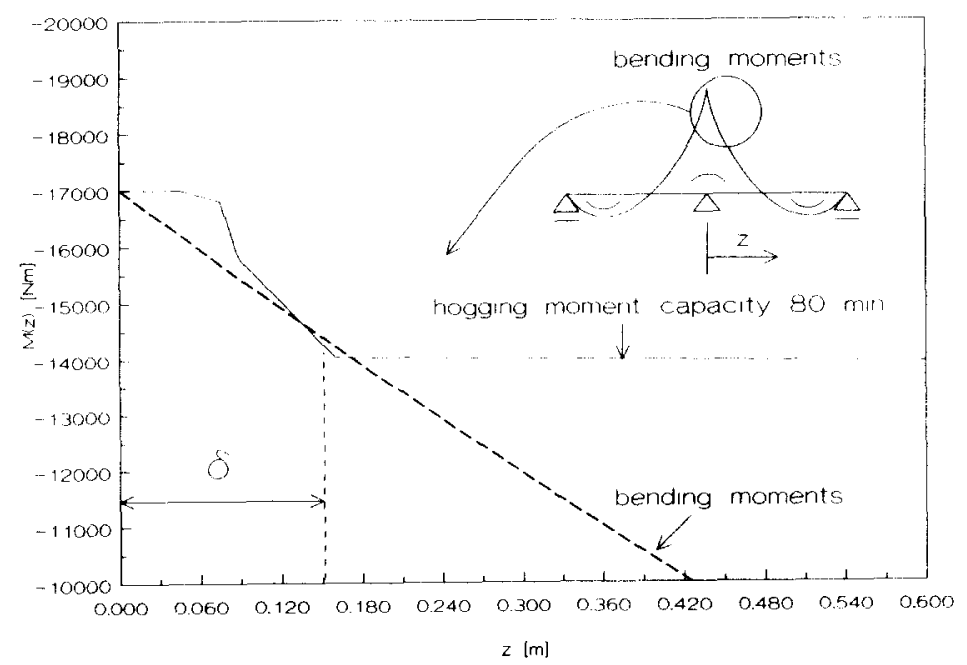

Fig. 9. Comparison bending moments and plastic moment capacity near an internal support for the unprotected slab. 


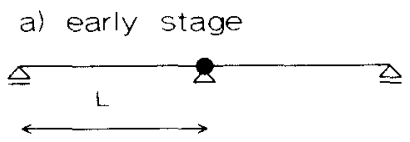

b) during fire-exposure

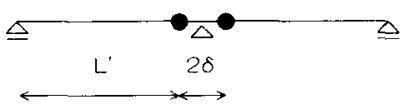

c) at fallure

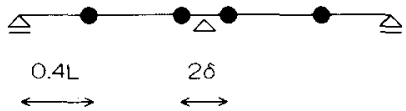

Fig. 10. Transformation if failure mechanism: reduction of span.

(see Fig. 10). Note that this means that the system length reduces from $L=4.0$ to $(L-\delta)=3.85 \mathrm{~m}$.

In the case of the protected slabs, the hogging moment capacity does cover the bending moments (see Fig. 11). This means that the plastic hinge will not move, and remains at the centre of the internal support, yielding a 'traditional' failure mechanism with three plastic hinges as depicted in Fig. 12.

First we consider an unprotected composite slab, and we ignore any positive effect due to thermal shielding. Assume that at failure the plastic hinge in the spans is located at a distance of 0.4 times the span from the

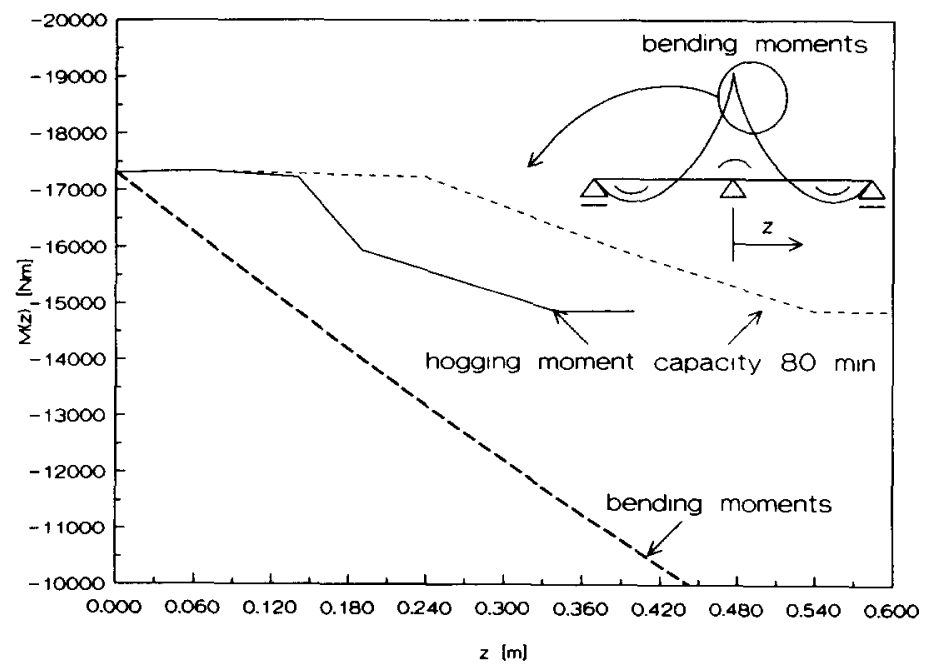

Fig. 11. Comparison bending moments and plastic moment capacity near an internal support for the protected slabs. $L_{\text {prot }}:-, 100 \mathrm{~mm} ;---, 30 \mathrm{~mm}$. 


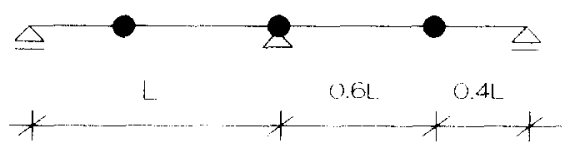

Fig. 12. Expected failure mechanism of the investigated partially protected slabs.

end supports, (see Figs 3 and 12). On the basis of this failure mechanism, we can approximate the fire resistance by solving the time $t$ from eqn (1):

$$
M_{\mathrm{p}}^{+}(t)+0 \cdot 4 M_{\mathrm{p}}^{-}(t) \approx 1 / 8 q L^{2}
$$

where

$M_{\mathrm{p}}^{+}(t)=$ sagging plastic moment capacity at time $t(\mathrm{Nm})$,

$M_{\mathrm{p}}^{-}(t)=$ hogging plastic moment capacity at time $t(\mathrm{Nm})$,

$q=$ total distributed load on composite slab $\left(\mathrm{N} / \mathrm{m}^{2}\right)$,

$L \quad=\operatorname{span}(\mathrm{m})$.

In Fig. 13, both hogging and sagging moment capacity are given as a function of time, ignoring any positive influence of thermal shielding and protection material. Furthermore, the results of calculations based on the existing rules, i.e. EC4 (which is basically a rectagular stress-block method), are plotted as well.

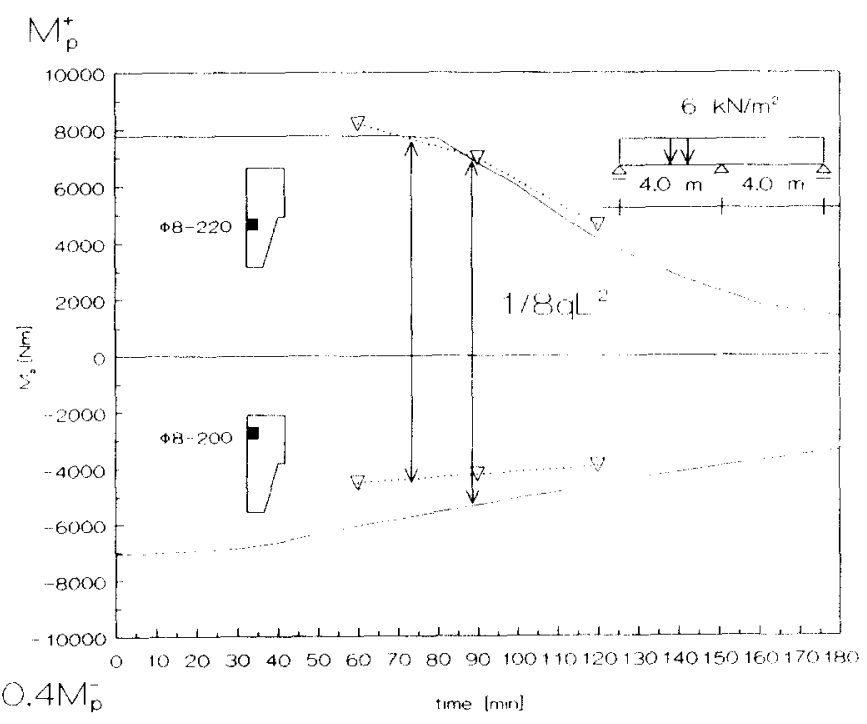

Fig. 13. Comparison of the predictions of the fire resistance on the basis of elementary plastic theory, ignoring the influence of partial protection, according to the numerical models and the existing Eurocode $4 .^{5} \ldots, \mathbf{M}-\kappa$ model unprotected; $\cdots \nabla \cdot \cdot$, EC4 1992. 
From Fig. 13 it follows:

- the sagging plastic moment capacity calculated with EC4 is in good agreement with the cross-sectional model;

- EC4 is quite conservative with respect to the hogging moment capacity (this is probably caused by the fact that EC4 reduces the composite slab to a concrete slab with a height equal to the mean thickness of the composite slab);

- the fire resistance calculated on the basis of EC4 amounts to approximately $73 \mathrm{~min}$;

- a more sophisticated analysis by means of the cross-sectional model yields a fire resistance of some $88 \mathrm{~min}(+20 \%$ !) (this means a fire resistance class of $60 \mathrm{~min}$ ).

When taking the effect of thermal shielding into account for the unprotected slab $\left(L_{\text {prot }}=0\right)$, use should be made of the reduced system length $L^{\prime}=(L-\delta)$ and the influenced hogging plastic moment capacity as a function of time:

$$
M_{\mathrm{p}}^{+}(t)+0 \cdot 4 M_{\mathrm{p}}^{-}(t) \approx 1 / 8 q(L-\delta)^{2}
$$

For protected slabs, we should use the full system length $L$, but we can apply the hogging plastic moment capacity at room temperature conditions:

$$
M_{\mathrm{p}}^{+}(t)+0 \cdot 4 M_{\mathrm{p}}^{-}(0) \approx 1 / 8 q L^{2}
$$

In Fig. 14, both hogging and sagging moment capacity are given as a function of time, for both unprotected and protected slabs. Equation (2) yields a fire resistance for the unprotected slab of some $97 \mathrm{~min}$. This is not only more than $10 \%$ higher than the result of the calculation in which the positive influence of the protection material is ignored, but it is also an improvement in a full fire resistance class (from 60 to $90 \mathrm{~min}$ ). Equation (3) yields an even higher fire resistance of the protected slab of $109 \mathrm{~min}$ : this is almost an improvement in the two fire resistance classes. It is noted in this respect, that partial protection of the composite slab over a length of only $100 \mathrm{~mm}$ might already yield the above effect, and that partial protection over a larger distance is therefore, for the investigated case, not necessary.

In Table 2, the results of all calculations are summarised in terms of the fire resistance. The corresponding failure mechanism is given as well.

In order to verify the above and make more general conclusions on this subject, further numerical and experimental work are planned. It is felt 


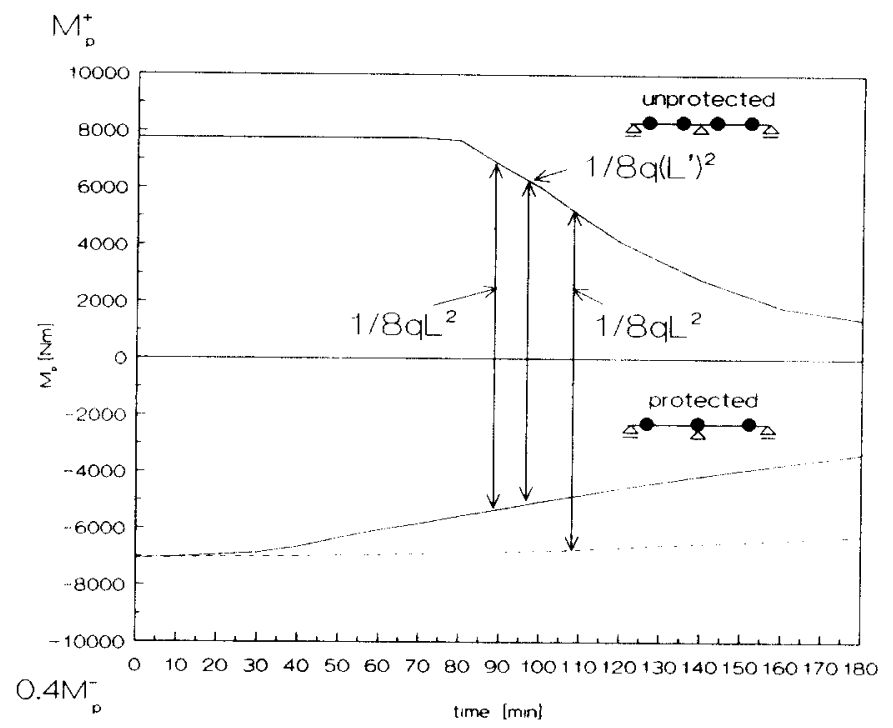

Fig. 14. Positive influence of partial protection on the fire resistance of composite slabs. M- $\kappa$ model unprotected; ---, part. prot. $10 \mathrm{~mm}$.

TABLE 2

Comparison of Different Calculation Methods for the Fire Resistance of Two-Span Composite slabs

\begin{tabular}{|c|c|c|c|}
\hline \multirow[t]{2}{*}{ Calculation } & \multicolumn{2}{|c|}{ Fire resistance } & \multirow[t]{2}{*}{ Failure mechanism } \\
\hline & $(\min )$ & Class & \\
\hline EC 4 & 73 & 60 & $\triangleq \quad 8 \quad \triangleq$ \\
\hline$M-\kappa$ model: ignoring thermal shielding & 88 & 60 & $8 \quad \cong$ \\
\hline$M-\kappa$ model: $L_{\text {prot }}=0 \mathrm{~mm}$ & 97 & 90 & 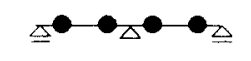 \\
\hline$M-\kappa$ model: $L_{\text {prot }}=100 \mathrm{~mm}$ & 108 & 90 & $8 \bullet \underline{\square}$ \\
\hline$M-\kappa$ model: $L_{\mathrm{prot}}=300 \mathrm{~mm}$ & 108 & 90 & $8-2$ \\
\hline
\end{tabular}

that the idea of partial protection near internal supports provides an easy and economical alternative to enhance the fire resistance of composite slabs.

\section{SUMMARY AND CONCLUSIONS}

TNO Building and Construction Research and Delft University of Technology jointly share research activities on fire-exposed composite slabs. This research is part of an international project on fire-exposed composite 
structures, co-sponsored by the European Coal and Steel Community. The aim of the ECSC project is the establishment of simple calculation rules.

In the first project phase, simply supported slabs were examined. Research is now focusing on the behaviour of continuous composite slabs. Transient heat flow near internal supports was investigated using the general purpose three-dimensional finite element package, DIANA. In particular, the influence of partial fire protection of the composite slabs, near internal supports consisting of an insulated steel section was studied. As a results of these calculations, the following conclusions can be drawn:

- The area in the composite slabs near the internal supports, in which the temperature development is favourably influenced approximately equals the length of the protected area plus the height of the composite slab. This also holds for the hogging plastic moment capacity.

- The existing calculation rules as adopted in EC4 yield conservative fire resistances (for the investigated case, assuming conditions which allow use of elementary plastic theory).

- Calculations with advanced numerical models reveal the possibilities of partial protection of composite slabs near internal supports. The models indicate that the fire resistance can be improved by $20 \%$, a full fire resistance class, even with a small additional amount of protection material.

Further numerical and experimental research is planned in order to verify this economic alternative to enhance the fire resistance.

\section{ACKNOWLEDGEMENT}

The financial support of the European Coal and Steel Community, under grant ECSC 7210/SA-509 is gratefully acknowledged.

\section{REFERENCES}

1. Klingsch, W. \& Kordina, E. H. K., Fire resistance of composite columns of concrete filled hollow sections. CIDECT report 15 C1/C2-83/27, ECSC7210/SA-1-108, 1983.

2. Klingsch, W. \& Wittbecker, F. W., Fire resistance of hollow section composite columns of small cross sections. CIDECT report 15 G-88/3E, ECSC-7210/SA$1-108,1988$.

3. Schleich, J. B., Computer assisted analysis of the fire resistance of steel and composite concrete-steel structures. ECSC-7210/SA-502, 1987. 
4. Hamerlinck, A. F., The behaviour of fire-exposed composite steel/concrete slabs. Docotral thesis, Eidenhoven University of Technology, 1991.

5. Eurocode 4, Design of Composite Steel and Concrete Structures, Part 1.2: Structural Fire Design, draft, 1992.

6. Haar, P. W. \& van de, Smit, C. L., Investigation into the fire resistance of steel structures insulated with Strong-Seal sprayed mortar FP-1A. TNO Building and Construction Research, Report B-89-373, 1989.

7. Both, C., Stark, J. W. B. \& Twilt, L., Thermal shielding in continuous span composite slabs. Proceedings ASCE Conference on Composite Construction II, Potosi, Missouri, 1992. 